Original Research

\title{
Rapid Startup of Simultaneous Nitrogen and Phosphorus Removal (SNPR) Process and the Bacterial Community Dynamics in a GSBR
}

\author{
Xin Xin*, Ziling Wang \\ College of Resources and Environment, Chengdu University of Information Technology, Chengdu, China
}

Received: 14 March 2018

Accepted: 29 June 2018

\begin{abstract}
This study inoculated aerobic granular sludge (AGS) in a sequencing batch reactor (SBR) treatment for low carbon nitrogen $(\mathrm{COD} / \mathrm{N})$ ratio wastewater, and gradually reduced the DO concentration in order to achieve the rapid startup of the simultaneous nitrogen and phosphorous removal (SNPR) process. Meanwhile, the microbial community dynamics at different DO levels were analyzed by high-throughput sequencing. The removal efficiencies of total nitrogen (TN) and phosphorus (TP) were significantly affected as different dissolved oxygen (DO) concentrations $(2.0,1.2$ and $0.8 \mathrm{mg} / \mathrm{L}$ ) in stages I, II and III, respectively. When DO concentration was reduced to $0.8 \mathrm{mg} / \mathrm{L}$ (stage III), the SNPR process was successfully implemented and the removal efficiencies of TN and TP were up to $77.30 \%$ and $85.78 \%$, respectively. A total of 40,983 effective $16 \mathrm{~S}$ rRNA gene sequences were generated from four samples (1-4) that widely represented microbial community diversity. The dominant phyla transformed from Candidate_division_TM7 (the relative abundance of $68.08 \%$ ) and proteobacteria $(25.78 \%)$ to Firmicutes $(47.57 \%)$ and proteobacteria $(41.49 \%)$ when DO concentration was decreased from $2.0 \mathrm{mg} / \mathrm{L}$ (stage I) to $0.8 \mathrm{mg} / \mathrm{L}$ (stage III). Moreover, Kluyvera, Peptostreptococcaceae_incertae_ sedis, Clostridium_sensu_strict_1, Trichococcus, Denitratisoma, Clostridium_sensu_stricto_13 and Raoultell were the most abundant genus in the SNPR process. Among these communities, Clostridium sensu_strict_1, Clostridium_sensu_stricto_13 and Denitratisoma were considered the main organisms responsible for simultaneous nitrogen and phosphorus removal.
\end{abstract}

Keywords: high-throughput sequencing, microbial communities, aerobic granule sludge, simultaneous nitrogen and phosphorus removal, low $\mathrm{COD} / \mathrm{N}$ ratio domestic wastewater

*e-mail: xx@cuit.edu.cn 


\section{Introduction}

Biological nutrient and phosphorus removal technology is commonly applied to treat municipal and industrial wastewater because of its economic and efficient characteristics [1-2]. Traditional processes of biological nitrogen removal involve two stages of nitrification and denitrification. Nitrification is the process of converting ammonia nitrogen into nitrite and/or nitrates by autotrophic nitrifying microbes under aerobic conditions. Denitrification requires the transfer of nitrate or nitrite to gaseous nitrogen by denitrifying bacteria under anaerobic or anoxic conditions. Meanwhile, phosphorus removal should be realized by anaerobic phosphorus release and aerobic phosphorus uptake [3]. The dentrification process and anaerobic phosphorus release should both consume sufficient amounts of organic matter to provide energy. However, nowadays large amounts of wastewater with low carbon nitrogen $(\mathrm{COD} / \mathrm{N})$ ratio were discharged due to the improvement of living standards and diet changes in China. It would be unsatisfactorily efficient of nitrogen and phosphorus removal to choose conventional activated sludge to treat the low $\mathrm{COD} / \mathrm{N}$ ratio wastewater because of insufficient amounts of organic carbon [4].

Resent research certified that simultaneous nitrification and denitrification (SND) could occur in a bioreactor [5]. There would be mainly three separate organisms, including nitrifying, denitrifying bacteria and polyphosphate accumulating organisms (PAOs) due to the simultaneous nitrogen and phosphorus removal occurring in the SND process. However, there is an obvious contradiction between PAOs and denitrifying bacteria for consuming carbon sources, which leads to limit the efficiency of combined nitrogen and phosphorus removal. As we all know, both processes involve nitrite as an intermediate in the biological nitrogen removal process. If denitrification mainly undergoes nitrite reduction, SND can be theoretically reduced to $40 \%$ carbon sources and resolve the contradiction between phosphorus and denitrifying bacteria for carbon source consumption [6-7]. Thus, SND via nitrite reaction (SSND) may be appropriate to treat the low $\mathrm{COD} / \mathrm{N}$ ratio wastewater and be beneficial to achieve simultaneous nitrogen and phosphorous removal (SNPR). This is usually achieved in the SNPR process by adjusting the DO concentration. But it is difficult to control the proper DO level in a dynamitic bioreactor [8]. Extremely low DO concentrations likely affect the rate of nitrification and nitrite accumulation, and possibly inhibit phosphorus absorption. By contrast, very high DO concentrations may influence the accumulation of nitrate and produce energy wastes [6, 9-10].

Aerobic granular sludge (AGS) is a promising technology for wastewater treatment because of several advantages, such as good settling property, high biomass, compacted granular structure and the ability to withstand high organic loading [11-12]. Moreover, the dense spherical structure of granules with aerobic zone, anoxic zone and anaerobic zone could help to form DO gradient and enhance the efficiency of denitrification and phosphorus removal [13]. Therefore, AGS could be beneficial to combined nitrogen and phosphorus removal [14].

Meanwhile, the analysis of microbial communities could be helpful for developing appropriate biological treatment processes and to optimize reaction conditions [15]. However, recent studies have rarely reported about the bacterial communities in the activated sludge, especially regarding the changes of bacterial communities in a sequencing batch reactor with aerobic granular sludge (GSBR) treatment for the low $\mathrm{COD} / \mathrm{N}$ ratio sewage under different $\mathrm{DO}$ conditions. Few published studies use fluorescent in situ hybridization (FISH) to quantify the composition of phosphorus and nitrogen-removing bacteria [16]. Another recently published study analyzed the bacterial communities in the sludge granules using high polymerase chain reaction (PCR)-denaturing gradient gel electrophoresis (DGGE) [17]. However, the results of previous studies mainly focused on the particular bacteria, such as ammonia-oxidizing bacteria (AOB) and nitrite-oxidizing bacteria (NOB). High-throughput sequencing is a second-generation DNA sequencing platform used to investigate the microbial diversity of environmental samples because this platform provides sufficient sequencing depth to cover complex microbial communities [18]. This technique has been applied to analyze microbial communities in wastewater [19-21]. High-throughput sequencing can also help illuminate the microbial community evolution caused by the variation of different conditions.

Therefore, this study inoculated the aerobic granular sludge in the sequencing batch reactor (GSBR) and gradually reduced the DO concentration in order to achieve the rapid startup of the SNPR process. This study aimed to a) to alter DO concentrations and to determine the optimum operational parameters for the SNPR in GSBR for the low COD/TN ratio sewage treatment and b) investigate bacterial community dynamics with different DO levels in GSBR through high-throughput sequencing.

\section{Material and Methods}

\section{Reactor Description}

The experiments were carried out in a $1.5 \mathrm{~L}$ lab-scale GSBR (Fig. 1) operated in a $12 \mathrm{~h}$ time per cycle with $5 \mathrm{~min}$ of feeding, $360 \mathrm{~min}$ of aeration reaction, $5 \mathrm{~min}$ of settling, $10 \mathrm{~min}$ of decanting and $340 \mathrm{~min}$ of idling. The volume exchange ratio was about $50 \%$. Aeration was achieved through an air diffuser placed at the bottom of the reactor, and the DO concentration was controlled by gas flow controllers. The GSBR operation period was divided into three stages based on the different DO concentrations: Stage I (1 10 d), Stage 


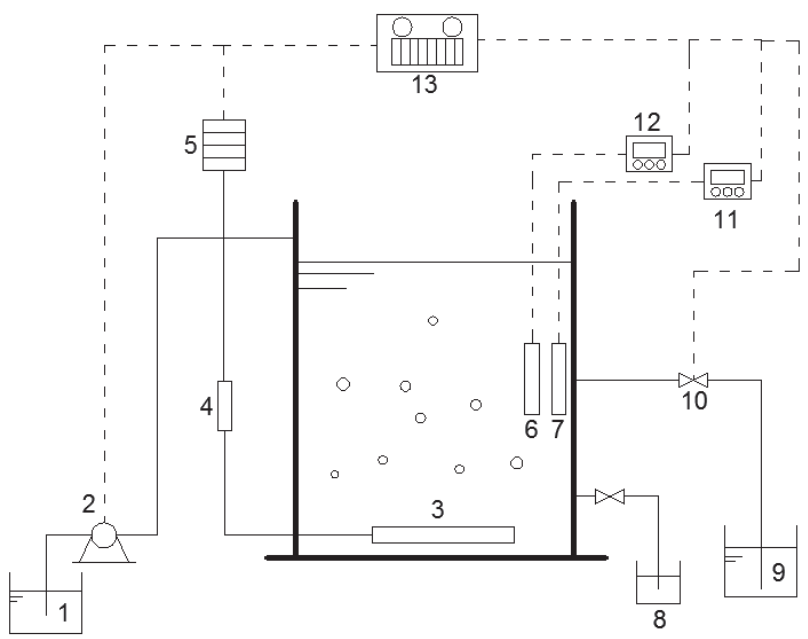

Fig. 1. Schematic diagram of GSBR; numbers 1-13 represent, sequentially, the influent tank, feed pump, aeration bar, gas flow meter, air pump, $\mathrm{pH}$ meter probe, DO meter probe, excess sludge tank, effluent tank, controlling valve, DO meter, $\mathrm{pH}$ meter and automatic control system.

II (11 20 d) and Stage III (21 60 d) were performed at average DO concentrations of 2.0, 1.2 and $0.8 \mathrm{mg} / \mathrm{L}$, respectively. The temperature was controlled at $28 \sim 30^{\circ} \mathrm{C}$ during the experiment using a thermostatic jacket.

\section{Experimental Wastewater and Seed Sludge}

The inoculated aerobic granular sludge (AGS) was obtained from our previous study [22]. The sludge was yellow, and its diameter and sludge volume index were approximately $0.6 \sim 1.5 \mathrm{~mm}$ and $38.1 \mathrm{~mL} / \mathrm{g}$, respectively. In order to minimize variability in the experiment we used synthetic wastewater. Glucose and sodium citrate were utilized as carbon sources, ammonium chloride was considered as a nitrogen source and dipotassium phosphate was used as a microbial phosphorus source. Meanwhile, the composition of synthetic wastewater also contained some inorganic salts and trace elements: $10 \mathrm{mg} / \mathrm{L} \mathrm{MgSO}_{4}, 10 \mathrm{mg} / \mathrm{L} \mathrm{FeSO}_{4}$ and $40 \mathrm{mg} / \mathrm{L} \mathrm{CaCl}_{2}$. The main indicators of sewage were as follows: $\rho$ (COD) $200 \sim 300 \mathrm{mg} / \mathrm{L}, \rho\left(\mathrm{NH}_{4}^{+}-\mathrm{N}\right) \quad 50 \sim 60 \mathrm{mg} / \mathrm{L}$, $\rho$ (TP) $2.0 \sim 3.5 \mathrm{mg} / \mathrm{L}$ and $\mathrm{pH} 7.5 \sim 7.8$.

\section{DNA extraction, PCR Amplification and High-Throughput Sequencing}

The bacterial communities of GSBR under each condition were investigated through Illumina highthroughput sequencing. Sludge samples were collected on days 1 (inoculation sludge, sample 1), 10 (sample 2), 20 (sample 3) and 59 (sample 4). After the samples were collected they were immediately fixed in $50 \%(\mathrm{v} / \mathrm{v})$ ethanol aqueous solution and stored at $-80^{\circ} \mathrm{C}$ until DNA extraction [23]. DNA in the AGS samples was extracted using a 3S DNA isolation kit for environmental samples (Bocai Biology, Shanghai, China) in accordance with the manufacturer's instructions. The DNA extracts were stored at $-20^{\circ} \mathrm{C}$ for subsequent PCR amplification. The V3 and V4 regions of the $16 \mathrm{~S}$ rDNA gene were selected for PCR. The primers were 338 F (5'ACTCCTACG GGAGGCAGCA-3') and 806R (5'GGACTACHVGGGTWTCTAAT-3'). PCR amplification was conducted in a $20 \mu \mathrm{L}$ reaction mixture composed of $4 \mu \mathrm{L}$ of $5 \times$ FastPfu Buffer, $2 \mu \mathrm{L}$ of $2.5 \mathrm{mM}$ dNTPs, $0.4 \mu \mathrm{L}$ of forward primer $(5 \mu \mathrm{M})$, $0.4 \mu \mathrm{L}$ of reverse primers $(5 \mu \mathrm{M}), 0.4 \mu \mathrm{L}$ of FastPfu polymerase and $10 \mathrm{ng}$ of DNA template. PCR was performed under the following conditions: initial denaturation at $95^{\circ} \mathrm{C}$ for $2 \mathrm{~min}$ followed by 30 cycles of denaturation at $95^{\circ} \mathrm{C}$ for $30 \mathrm{~s}$, annealing at $55^{\circ} \mathrm{C}$ for $30 \mathrm{~s}$, extension at $72^{\circ} \mathrm{C}$ for $30 \mathrm{~s}$ and a final extension at $72^{\circ} \mathrm{C}$ for $5 \mathrm{~min}$. The PCR products were examined on a $2 \%(\mathrm{w} / \mathrm{v})$ agarose gel, and the band was extracted and purified with AxyPrepDNA Gel (Axygen, CA, USA) and PCR clean-up system. Approximately $500 \mathrm{ng}$ of purified PCR products for different sludge samples were sent to Shanghai Majorbio Bio-Pharm Technology Co., Ltd. (Shanghai, China) for Illumina MiSeq sequencing.

\section{Sequence Analysis and Phylogenetic Classification}

Sequencing data were processed through read trimming and identification of V3-V4 sequences, followed by filtering and assigning of operational taxonomic units (OTUs). OTUs were identified with a cutoff of $97 \%$ identity. The reads from filtered OTUs were processed using Quantitative Insights into Microbial Ecology to construct a representative sequence for each OTU. The representative sequences were assigned at different taxonomic levels (from phylum to genus) to the SILVA dataset of bacteria following the Bayesian approach and cutoff of 97\%. The clusters were constructed at a $3 \%$ dissimilarity cutoff and served as OTUs for generating predictive rarefaction models [20]. A Venn diagram using the $\mathrm{R}$ package (http://www.R-project.org/) with shared and unique OTUs was used to depict the similarities and differences among the four communities. The interrelationships among the bacterial communities in the different samples in the four stages were visualized through principal component analysis (PCA).

\section{Analytical Methods}

Ammonium nitrogen, nitrite nitrogen, nitrate nitrogen, total nitrogen (TN), COD and total phosphorus (TP) were analyzed in accordance with standard methods [24]. DO concentrations were measured using a DO meter (JC516-DO200, China). 


\section{Results and Discussion}

\section{Treatment Performance of GSBR}

The variations of influent and effluent COD, ammonia, $\mathrm{NO}_{2}^{-}-\mathrm{N}$ and $\mathrm{NO}_{3}^{-}-\mathrm{N}$, and $\mathrm{TN}$ and $\mathrm{TP}$ concentrations in the GSBR operational stage are shown in Fig. 2. The bioreactor exhibited different removal efficiencies for different pollutants. The average COD removal efficiency was $90.13 \%$ in stage I, and it had a slight decrease to $88.55 \%$ in stage II, and then maintained at $84.15 \%$ in stage III. Meanwhile, Fig. 2b) showed that the ammonia average removal efficiency was slightly changed with the DO reduction. Although the average removal efficiency of ammonia in stage I reached more than $90 \%$, it was slightly reduced to $82.70 \%$ at the end of stage II $(20 \mathrm{~d})$. After about 20 days of sludge adaptation, the average ammonia removal efficiency was $90.88 \%$ (40 60 d). In contrast to COD and ammonia removal efficiency, the TN removal efficiency considerably increased and the $\mathrm{NO}_{3}^{-}-\mathrm{N}$ concentration in effluent notably declined as the DO levels decreased. The average removal efficiencies of $\mathrm{TN}$ increased from $41.41 \%$ in stage I to $77.30 \%$ in stage III (Fig. 2d). In addition, the average $\mathrm{NO}_{3}^{-}-\mathrm{N}$ concentrations in the effluent were 47.87, 10.43 and $3.24 \mathrm{mg} / \mathrm{L}$ in stages I, II and III. The $\mathrm{NO}_{2}^{-}-\mathrm{N}$ concentration in the effluent of the reactor slightly increased as the DO concentration declined, the average content of which was $2.69,3.34$ and $4.04 \mathrm{mg} / \mathrm{L}$ in stages I, II and III, respectively. During the whole reactor operation, the $\mathrm{NO}_{3}^{-}-\mathrm{N}$ and $\mathrm{TN}$ concentrations in the effluent significantly decreased, and the accumulation of $\mathrm{NO}_{2}^{-}-\mathrm{N}$ content was not evident with the gradual reduction of DO concentration (Fig. 2c). These results imply that the evident SND process occurred in the granular sludge system [25]. Meanwhile, TP removal efficiency (Fig. 2e) also increased, and the average TP removal efficiency was $39.90 \%$ in stage I and $85.78 \%$ in stage III. With the evident reduction of $\mathrm{TN}$ and TP contents in effluent, our results preliminarily indicated that phosphorus and nitrogen were simultaneously removed at stage III in GSBR.

Varying the DO concentrations likely affected the removal of TN and TP in GSBR, but no evident effects were observed in the COD and ammonia nitrogen removal in this study. The results further revealed that phosphorus and nitrogen could be effectively and simultaneously removed from GSBR by gradually reducing the DO concentration. In this study, the startup time of simultaneous phosphorus and nitrogen removal was shorter than that of other GSBR [26-27]. The TN and TP removal efficiencies of the GSBR $(77.30 \%$ and $85.78 \%)$ were much higher than those of GSBR described in previous reports (49\% and $71 \%$ ) [25]. This phenomenon occurred possibly because the gradual decrease in DO concentrations was conducive to the enrichment of nitrifying bacteria, denitrifying bacteria and phosphorus-accumulating bacteria. Wang reported the denitrification and phosphorus removal efficiency at $2 \sim 3 \mathrm{mg} / \mathrm{L} \mathrm{DO}$, but did not describe DO parameter optimization [26]. Previous studies
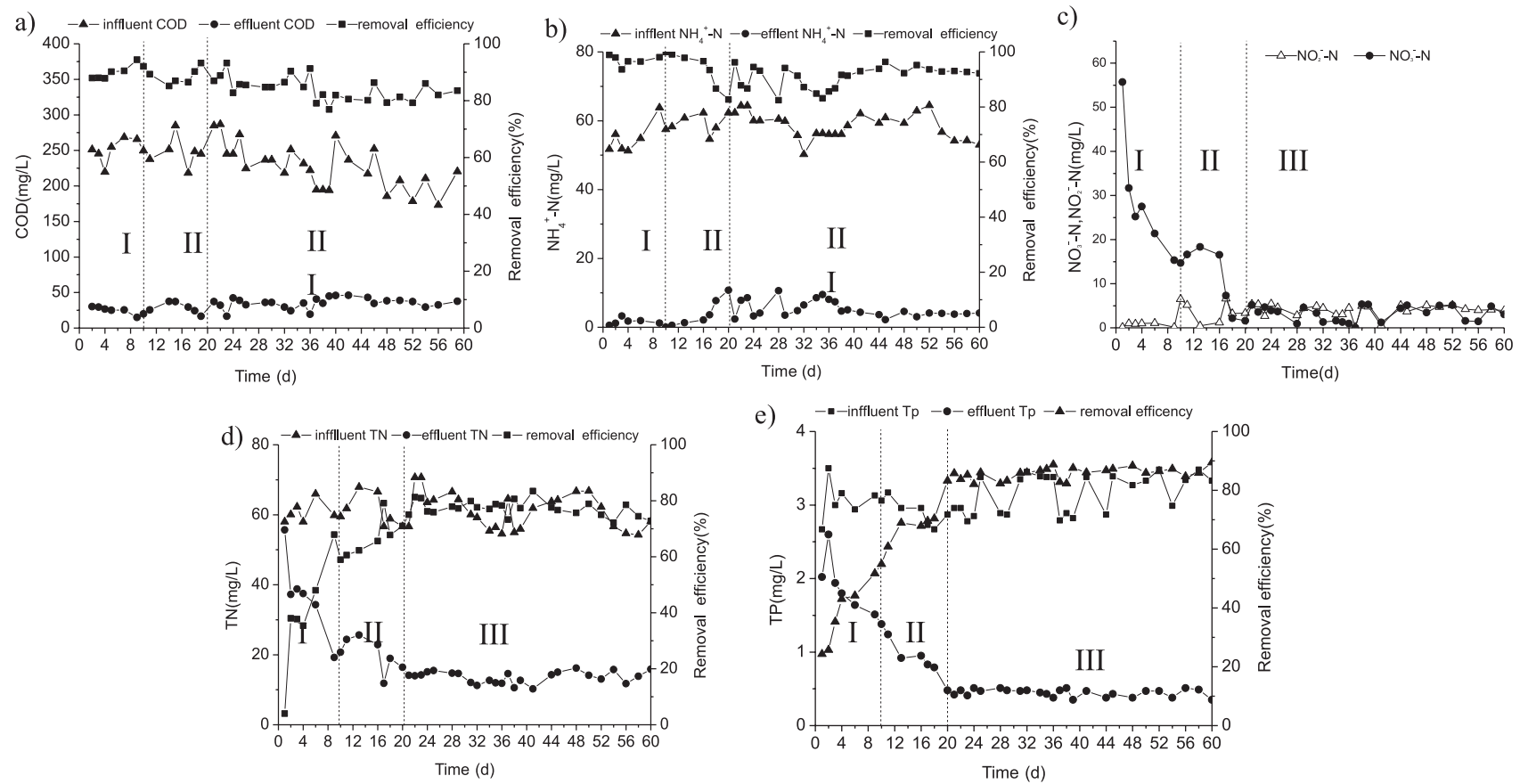

Fig. 2. Variations of: a) influent and effluent COD and COD removal efficiency, b) influent and effluent $\mathrm{NH}_{4}^{+}-\mathrm{N}^{-}$and $\mathrm{NH}_{4}^{+}-\mathrm{N}^{-}$removal efficiency, c) $\mathrm{NO}_{2}^{-}-\mathrm{N}$ and $\mathrm{NO}_{3}^{-}-\mathrm{N}$ concentrations in GSBR system, d) influent and effluent concentrations of TN and TN removal efficiency and e) concentrations of TP and TP removal efficiency. 
a)

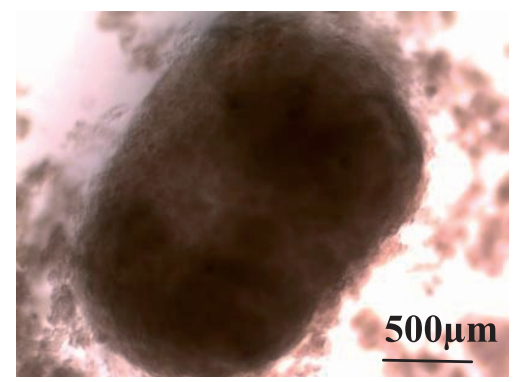

b)

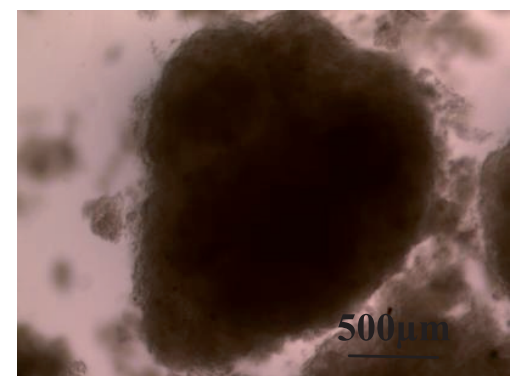

c)

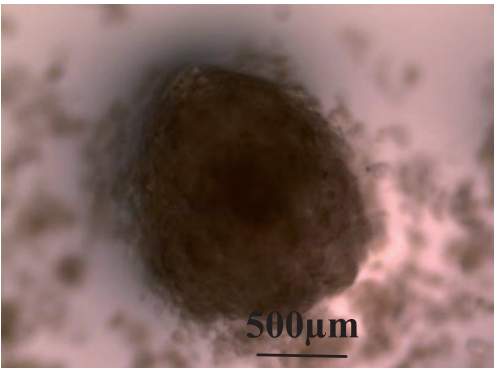

Fig. 3. Morphology of AGS in different stages: a) I, b) II and c) III.

revealed that high DO concentrations favor nitrification but limit denitrification; by contrast, low DO concentrations enhance denitrification [28]. de Kreuk and Loosdrecht van ever affirmed that the reduction of oxygen concentration to $40 \%$ of the saturation value $(\mathrm{DO}<3 \sim 4 \mathrm{mg} / \mathrm{L})$ causes the breaking up of granules [29]. However, the AGS structure in this study was integral in the reactor at a low DO concentration of $0.8 \mathrm{mg} / \mathrm{L}$ (Fig. 3). One possible reason for this observation is that domestic wastewater with low $\mathrm{COD} / \mathrm{N}$ ratios could reduce the growth rate of granules, and this finding is similar to that described in previous research [30]. In this study, the DO concentration needed in the GSBR system was about $60 \%$ lower than that of other GSBR systems [26-27, 31]. Compared with those in previous reports, the GSBR system in this study provides unique advantages for the treatment of domestic wastewater with low $\mathrm{COD} / \mathrm{N}$ ratios and avoids the need for external carbon source additions and low energy consumption.

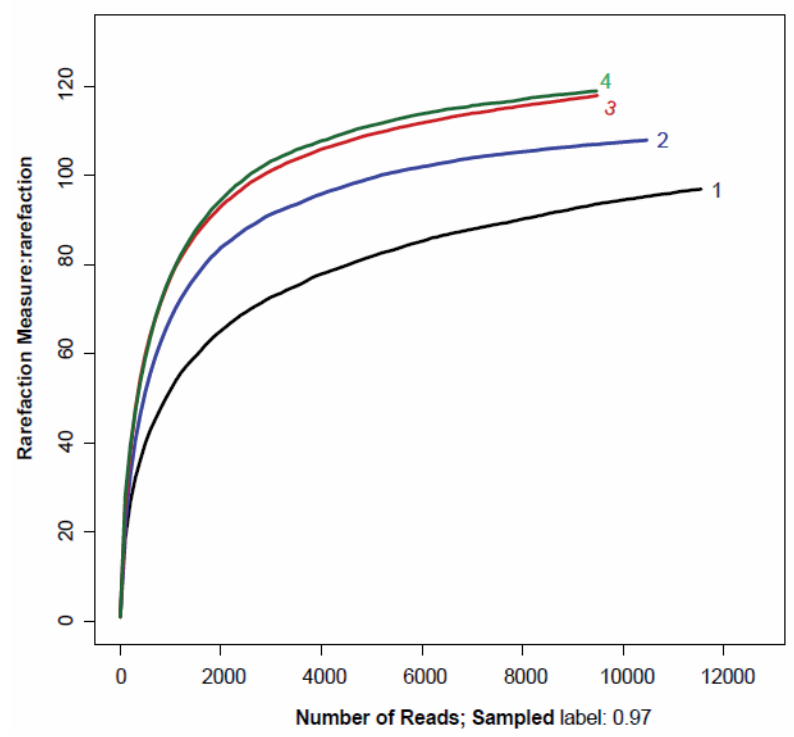

Fig. 4. Rarefaction curves of samples bacterial communities (OTUs were defined by $3 \%$ distances).

\section{Richness and Diversity of Bacteria Phylotypes of GSBR}

Rarefaction analysis was employed to standardize and compare the observed taxon richness between samples and to verify whether the sample is unequally sampled. A total of 40,983 effective sequences of the 16S rRNA gene were generated from four samples that widely represented the diversity of the microbial community. Over 9,400 sequences were obtained for each sample (Fig. 4). In total, 97 (sample 1), 108 (sample 2), 118 (sample 3) and 119 (sample 4) OTUs at a 3\% distance were obtained. Fig. 3 demonstrates that the bacterial phylotype richness of samples 3 and 4 were much higher than those of the other samples. This result implies that the bacterial species diversity was negatively related to the DO concentration. To evaluate the distribution of OTUs among the different samples, a Venn diagram was constructed (Fig. 5), which showed that 61 OTUs were common to all four samples. Meanwhile, sample 4 had 14 unique OTUs, which was higher than those of the three other samples.

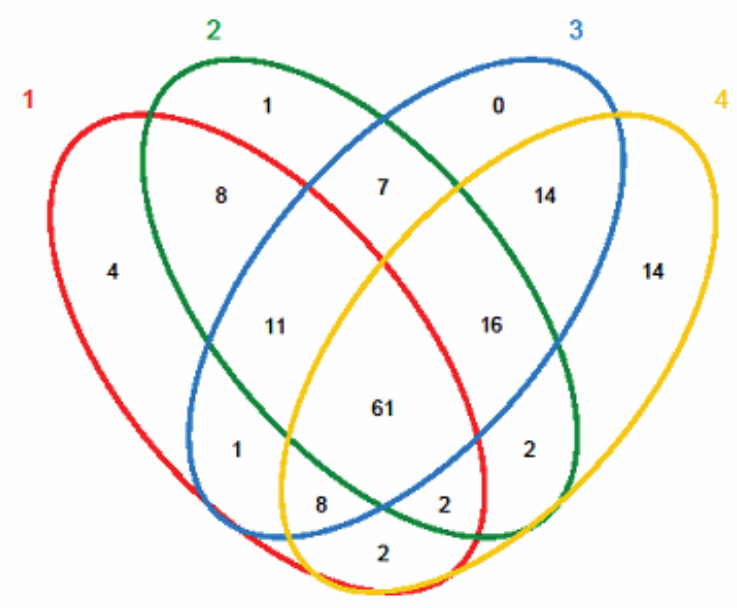

Fig. 5. Overlap of the four bacterial communities from samples based on OTU ( $3 \%$ distance), and the taxonomic identities of the shared OTUs at phylum level (the number in parentheses represents the total number of OTUs in that community). 
This observation initially implies that the bacterial populations of sample 4 were obviously different from those of the three other samples.

\section{Beta Diversity for Four Samples of GSBR}

The PCA (Fig. 6a) revealed that samples 2 and 3 were clustered together and were well separated from sample 1 (inoculation sludge); sample 4 was obviously separated from sample 1. Principal components 1 and 2 corresponded to $95.54 \%$ and $3.42 \%$ of the total community variations, respectively. These results show that different DO concentrations considerably affected the community structures. Moreover, clustering analysis revealed that bacterial communities in the four samples could be clustered into three groups (Fig. b): (1) Group I contained samples 2 and 3; (2) Group II contained sample 1; and (3) Group III contained sludge sample 4. Additionally, samples 2 and 3 were relatively close to

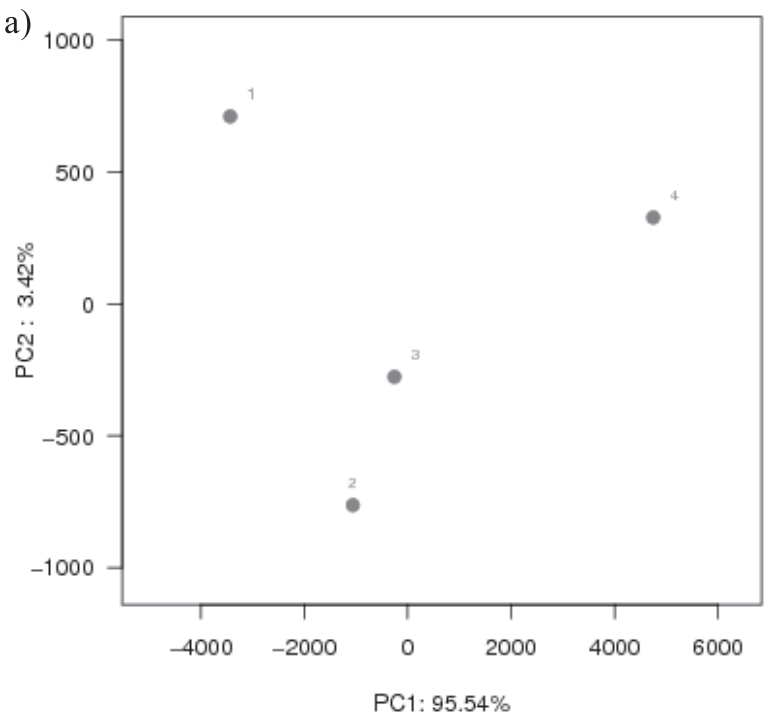

b)

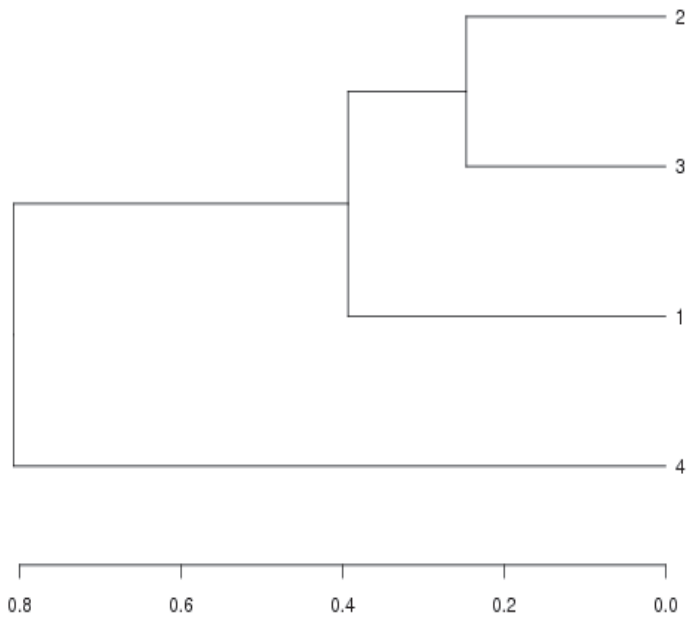

Fig. 6. Beta diversity for four samples: a) 2-D PCA analysis and b) phylogenetic tree (hierarchical cluster analysis using pairwise weighted UnifFrac distances). sample 1; however, sample 4 was relatively distant from the other samples. These results further illustrate that the bacterial communities between sample 4 and the three other samples had considerable changes.

\section{Bacterial Community Dynamics with Different DO Levels in GSBR}

The bacterial community distribution at the phylum level of four samples demonstrated similar diversities but different abundances. In total, eight phyla were identified, the most dominant being Candidate division TM7, Firmicutes, Proteobacteria and Bacteroidetes (Fig. 7a). With the decrease of DO concentration, the relative abundance of Candidate_division_TM7 was reduced from $67.81 \%$ in sample 1 to $2.7 \%$ in sample 4. However, the relative abundance of Firmicutes was lowest in sample $1(0.61 \%)$, higher in samples $2(7.09 \%)$ and $3(15.97 \%)$ and highest in sample $4(47.57 \%)$. Proteobacteria was the dominant bacteria in the four samples, but its relative abundance also considerably increased from $25.78 \%$ in sample 1 to $41.49 \%$ in sample 4. In addition, the relative abundances of Chloroflexi and Planctomycetes in sample 1 were only $0.04 \%$ and $0.02 \%$, respectively; however, an obvious increase of the two bacteria were observed in sample 4 at $1.69 \%$ and $1.73 \%$, respectively.

The bacterial community distribution at the genus level for the four samples is shown in Fig. 7b). The dominant populations in sample 1 included Candidate-division_TM7_norank (68.08\%), Comamonadaceae_unclassified (4.67\%), Rhodobacter (3.26\%), NKB5_norank (3.57\%), Devosia (3.02\%), Hyphomicrobiaceae (2.37\%), Flavobacterium (1.54\%) and Pseudoxanthomonas (1.49\%). In sample 2, a wider range of bacterial groups was identified as dominant: Candidate-division_TM7_norank (51.89\%), Shinella (9.45\%), Bosea (6.01\%), Flavobacterium (5.82\%), Peptostreptococcaceae_incertae_sedis (4.34\%) and Acinetobacter (1.83\%). The dominant populations in sample 3 were Candidate_division_TM7_norank (49.93\%), Peptostreptococcaceae_incertae_sedis $(8.53 \%)$, Shinella $(3.79 \%)$, Bosea $(5.32 \%)$, Clostridium sensu_stricto_1 (3.89\%), Clostridium_sensu_stricto_13 $(2.19 \%)$ and Arenimonas (3.02\%). However, the considerable changes in the microbial communities of sample 4 were different from those of other samples, such as Peptostreptococcaceae_incertae_sedis (21.1\%), Kluyvera (15.52\%), Trichococcus (12.2\%), Clostridium_sensu_stricto_1 (8.59\%), Shinella (1.76\%), Clostridium_sensu_stricto_13 (5.29\%), Denitratisoma (4.43\%), Ráoultella (4.6\%), Candidate-division_TM7 norank (2.5\%), Silanimonas (2.45\%), Limnobacter $(2.07 \%)$ and Terrimonas (1.76\%). During the whole reactor operation, the number of some bacterial species, such as Candidate_division_TM7_norank, Flavobacterium, NKB5 norank and Devosia was largely decreased because of their inability to adapt to low DO concentrations. On the contrary, several new 
microbial communities, such as Clostridium_sensu stricto_1, Clostridium_sensu_stricto_13, Kluyvera, Peptostreptococcaceae_incertae_sedis, Trichococcus,

a) Candidate_division_TM7 $68.08 \%$

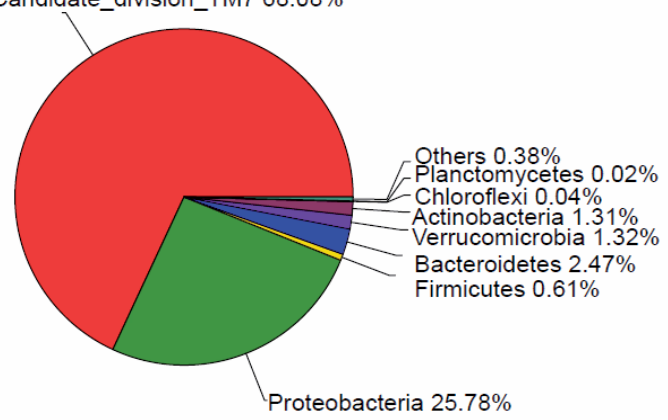

1

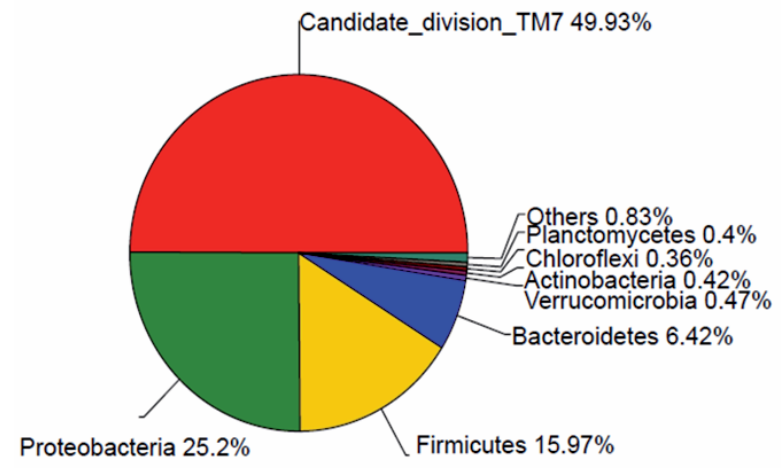

3

b)

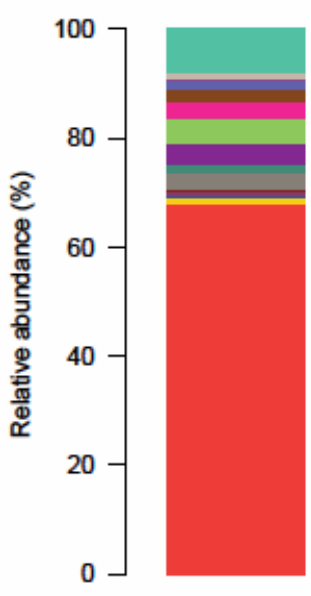

1
Denitratisoma, Raoultell, Silanimonas, Limnobacter and Terrimonas were observed. The relative abundance in stage III increased significantly.

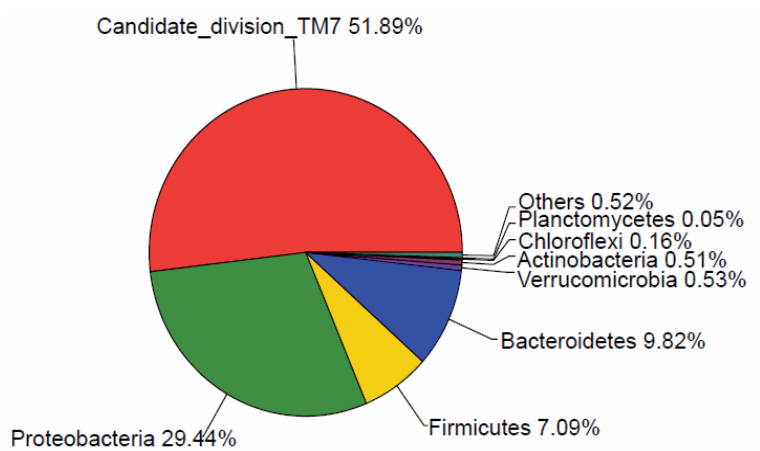

2
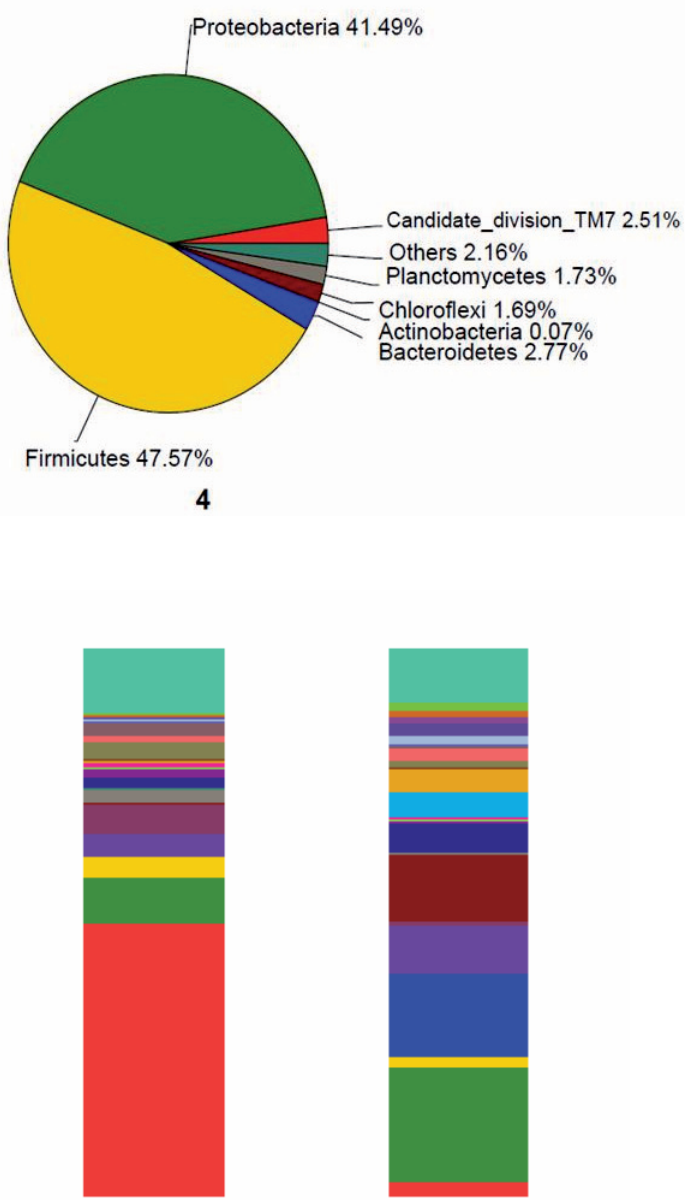

3

4

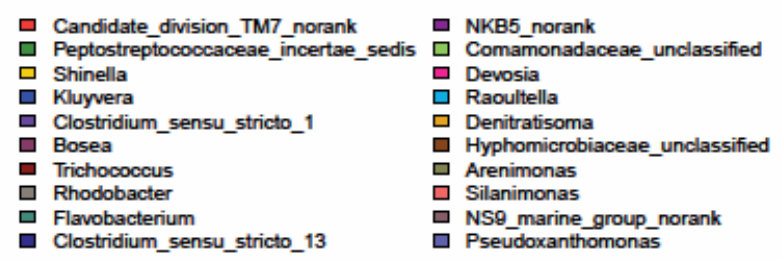

ㅁ. Terrimonas

Bdellovibrio

$\square$ Acinetobacter

Acinetobacter

ㅁ Caldilineace

ㅁ. SM1A02

O Kineosp

- Clostridium_sensu_stricto_13

NS9_marine_group_norank

Fig. 7. Distribution of bacterial community structures in four samples on the: a) phylum level and b) genus level; the abundance is presented in terms of a percentage of the total effective bacterial sequences in samples 1, 2, 3 and 4 . 
Candidate division TM7 norank is a species under the uncultured gamma_proteobacterium, the relative abundance of which in sample 1 (inoculation sludge) was the largest. As we all know, Candidate_division TM7 is one of the common microbial populations in sewage treatment plants [32], but its abundance in inoculation granular sludge is higher than that of the former. This result is related to the type of inoculation AGS. Mature AGS has been reported to contain a large number of Candidate_division_TM7, which agrees with the theory of filamentous fungi architecture [33]. At the same time, Proteobacteria mainly includes Alphaproteobacteria(Devosia, Hyphomicrob, and Rhodobacter), Betaproteobacteria(Comamonadac eae_unclassified), Gammaproteobacteria (NKB5 norank) and Deltaproteobacteria. Among these populations, Comamonadaceae was reported to be a promising heterotrophic nitrifier in a recent study [34]. Its abundance in sample 1 was evident, which led to higher nitrate nitrogen concentration in the effluent at the first few days in stage I. But its relative abundance was obviously declined with the gradual decrease of DO concentration. Meanwhile, some of the identified bacteria such as Peptostreptococcaceae_incertae_sedis, Shinella, Bosea and Flavobacterium began to increase in sample 2. These changes in bacterial communities might be related to the evident decrease of effluent nitrate nitrogen concentration. Moreover, the reactor started to show good TN removal performance at the end of stage I. As the DO concentration was further reduced to $1.2 \mathrm{mg} / \mathrm{L}$ (stage $\mathrm{II}$ ), the relative abundance of Flavobacterium in sample 3 decreased because it could not afford the low DO condition. Conversely, Clostridium_sensu_stricto_1, Clostridium_sensu_ stricto_13, Arenimonas and Peptostreptococcaceae incertae_sedis significantly increased. At the end of stage II, the reactor began to show good simultaneous nitrogen and phosphorus removal performances, but this improvement was not very stable. When the DO concentration was declined to $0.8 \mathrm{mg} / \mathrm{L}$ (stage III), Peptostreptococcaceae_incertae_sedis, Clostridium_sensu_stricto_1 and Clostridium_sensu_ stricto_13 increased continuously in sample 4. This result demonstrates that these species are negatively correlated to DO concentration. Some species, such as Trichococcus, Denitratisoma, Raoultell and Kluyvera were functional bacteria found in stage III. This indicated that these species prefer the low DO environment. GSBR showed optimal performances of simultaneous nitrogen and phosphorus removal at stage III. Peptostreptococcaceae_incertae_sedis and Trichococcus belong to the microbial populations of Firmicutes. Previous studies reported that Firmicutes could undergo nitrification and denitrification in aerobic or anaerobic environments [16]. In this study, the relative abundances of Trichococcus and Peptostreptococcaceae_incertae_sedis in sample 4 were obviously higher than those of other samples. This difference resulted in the good denitrification and phosphorus removal performance of the GSBR system in stage III. The relative abundances of Kluyvera and Denitratisoma were achieved at $15.52 \%$ and $4.43 \%$ in stage III, respectively. Kluyvera is a facultative anaerobic bacterium that can reduce nitrate to nitrite. Denitratisoma is a newly discovered species of denitrifying bacteria that can directly transfer nitrite to gaseous nitrogen [35]. This finding demonstrates that the low DO concentration of $0.8 \mathrm{mg} / \mathrm{L}$ was beneficial to the richness of Kluyvera and Denitratisoma, which reduced the effluent $\mathrm{NO}_{3}^{-}-\mathrm{N}, \mathrm{NO}_{2}^{-}-\mathrm{N}$ and $\mathrm{TN}$ content in stage III. Compared with that in sample 1 , the relative abundance of Chloroflexi and Planctomycetes also obviously increased. Chloroflexi had something to do with the enhanced removal system of biological phosphorus in wastewater treatment plants [36]. Planctomycetaceae belongs to a kind of anaerobic ammonia bacteria that can convert ammonia to gaseous nitrogen according to [37]. Given the low $\mathrm{COD} / \mathrm{N}$ ratio of influent wastewater and the low DO concentration in this study, Planctomycetaceae populations likely included several anaerobic ammonia-oxidizing species. Overall, this result indicates that Kluyvera, Peptostreptococcaceae incertae_sedis, Trichococcus, Denitratisoma and Planctomycetaceae are the dominant bacteria involved in total nitrogen removal under low DO concentrations. Clostridium is a type of denitrifying and phosphorusremoving bacteria [38]. This study found that the richness of Clostridium sensu_stricto_ 1 and Clostridium_sensu_stricto_ 13 in sample 4 was higher than that of other samples. At the same time, the GSBR system showed the best denitrification and phosphorus removal performance in stage III. This finding indicated that Clostridium_sensu_stricto_1 and Clostridium sensu_stricto_13 might $\bar{b}$ e the main bacterial species responsible for the removal of phosphorus. On the basis of the GSBR operational performance and microbial populations, we could initially conclude that nitrogen and phosphorus were simultaneously removed in stage III. Nitrogen and phosphorus were removed from wastewater mainly through SND and denitrifying phosphorus removal, respectively. Further studies should be performed to examine the possible metabolic pathways and mechanisms of combined nitrogen and phosphorus removal.

\section{Conclusions}

Simultaneous nitrogen and phosphorus removal (SNPR) in GSBR could be achieved rapidly within $21 \mathrm{~d}$ by gradually decreasing the DO concentrations. On the basis of the high-throughput sequencing data, this experiment found that the phylum-level bacterial communities in the four samples showed similar diversities but different abundances. Low DO concentrations could enrich Firmicutes but could decrease Candidate division TM7. The dominant microbial communities at a genus level 
in the SNPR bioreactor were as follows: Kluyvera, Peptostreptococcaceae_incertae_sedis, Clostridium sensu_stricto_1, Clostridium_sensu_stricto 13, Trichococcus, Denitratisoma and Raoultell. Among these communities, Clostridium_sensu_stricto_1, Clostridium_sensu_stricto_13 and Denitratisoma were possibly the primary organisms responsible for simultaneous nitrogen and phosphorus removal.

\section{Acknowledgements}

This work was supported jointly by a PeopleBenefiting Project of the Chengdu Science and Technology Bureau (grant No. 2015-HM01-00477-SF), a Scientific Research Project of the Sichuan Province Education Department (grant No. 17ZA0067) and a Youth Academic Leader Research Fund Project of Chengdu University of Information technology (grant No. J201614).

\section{Conflict of Interest}

The authors declare that they have no conflicts of interest in this work.

\section{References}

1. ZANETTI L., FRISON N., NOTA E., TOMIZIOLI M., BOLZONELLA D., FATONE F. Progress in realtime control applied to biological nitrogen removal from wastewater. A short review.Desalin. 286, 1, 2012.

2. ZENG W., Li B., WANG X.D., BAI X.L., PENG Y.Z. Ntegration of denitrifying phosphorus removal via nitrite pathway,simultaneous nitritation-denitritation and anammox treating carbon-limited municipal sewage. Bioresoure. Technology. 172, 356, 2014.

3. HE Q., WANG H., YANG X., ZHOU J., YE Y., CHEN D., YANG K. Culture of denitrifying phosphorus removal granules with different influent wastewater. Desalination and Water Treatment. 57 (37), 17247, 2016.

4. RICARDO B.C., ANNE-CLAIRE T., EÍAS R.F., RAMN M.P., JORGE G. Biotransformation of aromatic compounds from wastewaters containing $\mathrm{N}$ and/or $\mathrm{S}$, by nitrification/ denitrification: a review. Reviews in Environmental Science and Bio/Technology. 8, 325, 2009.

5. BAEK S.H., PAGILLA K.R. Simultaneous nitrification and denitrification of municipal wastewater in aerobic membrane bioreactors.Water Environment research.80 (2), 109, 2008

6. YANG S., YANG F.L. Nitrogen removal via shortcut simultaneous nitrificaition and denitrification in an intermittently arated moving bed membrane bioreactor. Journal of Hazardous Materials. 195 (15), 318, 2011.

7. ZHENG H.Y., LIU Y., GAO X.Y., AI G.M., MIAO L.L., LIU Z.P. Characterization of a marine origin aerobic nitrifying-denitrifying bacterium. Journal of Bioscience Bioengineer. 114 (1), 33, 2012.

8. KAMPSCHREUR M.J., TEMMINK H., KLEEREBEZEM R., JETTEN M.S.M., LOOSDRECHT M.V. Nitrous oxide emission during wastewater treatment. Water Research. 43, (17), 4093, 2009.

9. YUAN Q.Y., OLESZKIEWICZ J.A. Lowtemperature biological phosphorus removal and partial nitrification in a pilot sequencing batch reactor system. Water Science and Technology. 63 (12), 2802, 2011

10. LIU W.L., PENG T., MIAO Y.Y., ZHANG W.T., MA B., PENG Q.Z. Achievement of short-cut denitrification and enhancement of phosphorus removal in a SAOSBR process. China Environmental Science. 34 (12), 3062, 2014.

11. SAMUEL L., CHRISTOF H. Optimization of operation conditions for the startup of aerobic granular sludge reactors biologically removing carbon, nitrogen, and phosphorous. Water Research. 59, 58, 2014.

12. ZHAO X., CHEN Z.L., SHEN J.M., WANG X.C. Performance of aerobic granular sludge in different bioreactors. Environmental Technology. 35 (8), 938, 2014.

13. LOTITO A.M., FRATINO U., MANCINI A., BERGNA G., IACONI C.D. Effective aerobic granular sludge treatment of a real dyeing textile wastewater. International Biodeterioration and Biodegradation . 69 (7), 62, 2012.

14. HE Q., ZHOU J., WANG H., ZHANG J., WEI L. Microbial population dynamics during sludge granulation in an A/O/A sequencing batch reactor. Bioresource Technology. 214, 1, 2016b.

15. HESHAM A.E.L., QI R., YANG M. Comparison of bacterial community structures in two systems of a sewage treatment plant using PCR-DGGE analysis. Journal of Environmental Science. 23 (12), 2049, 2011.

16. ZOU J.T., LI Y.M., ZHANG L.L., WANG R.Y., SUN J. Understanding the impact of influent nitrogen concentration on granule size and microbial community in a granule-based enhanced biological phosphorus removal system. Bioresource Technology. 177, 209, 2015.

17. LI Y.M., ZOU J.T., ZHANG L.L., SUN J. Aerobic granular sludge for simultaneous accumulation of mineral phosphorus and removal of nitrogen via nitrite in wastewater. Bioresource Technology. 154, 178, 2014.

18. SHENDURE J., JI H. Next-generation DNA sequencing. Natural Biotechnology. 26 (10), 1135, 2008.

19. QUIGLEY L., O'SULLIVAN O., BERESFORD T.P., ROSS R.P., FITZGERALD G.F., COTTER P.D. Highthroughput sequencing for detection of subpopulations of bacteria not previously associated with artisanal cheeses. Appllied Microbiological and Biotechnology. 78 (16), 5717, 2012.

20. GUO F., ZHANG T. Biases during DNA extraction of activated sludge samples revealed by high throughput sequencing. Appllied Microbiological and Biotechnology . 97, 4607, 2013.

21. ZHANG Y., WANG X., HU M., LI P.F. Effect of hydraulic retention time (HRT) on the biodegradation of trichloroethylene wastewater and anaerobic bacterial community in the UASB reactor. Appllied Microbiological and Biotechnology. 99, 1977, 2015.

22. XIN X., LU H., YAO L., LENG L., GUAN L. Rapid Formation of Aerobic Granular Sludgeand Its Mechanism in a Continuous-Flow Bioreactor. Appllied Biochemistry and Biotechnology. 181, 424, 2017.

23. SHU D.T., HE Y.L., YUE H., WANG Q.Y. Microbial structures and community functions of anaerobic sludge in six full-scale wastewater treatment plants as revealed by 454 high-throughput pyrosequencing. Bioresoure Technology. 186, 163, 2015. 
24. APHA., AWWA., WPCF. Standard method for the examination of water and wastewater. $21^{\text {th }}$ ed. Washington DC 20001-3710, American Public Health Association 800 I Street, NW, 2005.

25. RAHIMI Y., TORABIAN A., MEHRDADI N., SHAHMORADI B. Simultaneous nitrificationdenitrification and phosphorus removal in a fixed bed sequencing batch reactor (FBSBR). Journal of Hazardous Materials. 185 (2-3), 852, 2011.

26. WANG F., LU S., WEI Y., JI M. Characteristics of aerobic granule and nitrogen and phosphorus removal in a SBR. Journal of Hazardous Materials.. 164, 1223, 2009.

27. BASSIN J.P., KLEERRBEZEM R., DEZOTTI M., VAN LOOSDRECHT M.C.M. Simultaneous nitrogen and phosphate removal in aerobic granular sludge reactors operated at different temperatures. Water Research. 46 (12), 3805, 2012.

28. DE KREUK M.K., HEIJNEN J.J., VAN LOOSDRECHT M.C.M. Simultaneous COD, nitrogen, and phosphate removal byaerobic granular sludge. Biotechnology Bioengineering. 90 (6), 761, 2005.

29. DE KREUK M.K., VAN LOOSDRECHT M.C.M. Selection of slow growing organisms as a means for improving aerobic granular sludge stability. Water Science andTechnology. 49, 9, 2004.

30. ZHANG C.Y., ZHANG H.M., YANG F.L. Diameter control and stability maintenance of aerobic granular sludge in an A/O/A SBR. Separation and Purification Technology. 149, 362, 2015.

31. DI B.G., TORREGROSSA M. Simultaneous nitrogen and organic carbon removal in aerobic granular sludge reactors operated with high dissolved oxygen concentration. Bioresoure Technology 142, 706, 2013.
32. YE L., ZHANG T. Bacterial communities in different sections of a municipal wastewater treatment plant revealed by $16 \mathrm{~S}$ rDNA 454 pyrosequencing. Appllied Microbiological and Biotechnology. 97, 2681, 2013.

33. JI S.L., CUI D.H., ZHOU M.J., LIU Y., QIN Z.P. Bacteria Diversity Analysis of Aerobic Granular Sludge for Nitrogen and Phosphorus Removal in Municipal Wastewater Treatment System. Journal of Beijing University technology. 39 (7), 1100, 2013.

34. MA Q., QU Y.Y., SHEN W.L., ZHANG Z.J.J.W., LIU Z.Y., LI D.X., HUI J.L., ZHOU J.T. Bacterial communitycompositionsof coking wastewater treatment plants in steel industry revealed by Illumina highthroughput sequencing. Bioresoure Technology. 179, 436, 2015.

35. CHANG Y.M., YANG Q., HAO C.B., SHANG H.T., JIANG T.S. Experimental Study of Autotrophic Denitrification Bacteria Through Bioaugmentation of Activated Sludge from Municipal Wastewater Plant. Journal of Environmental Science. 32 (4), 1210, 2011.

36. KRAGELUND C., LEVANTESI C., BORGERET A. Identity,abundanceand ecophysiology of filamentous Chloroflexi species present in activated sludge treatment plants. FEMS Microbiology Ecology. 59 (3), 671, 2007.

37. LIU D.Y., QIU Y.L., YUAN X.Z., SHUAI X.S., GUO R.B. Enrichment and Identification of Anaerobic Ammonium Oxidation Bacteria. Journal of Environmental Science. 9 (33), 3208, 2012.

38. MASZENAN A.M., SEVIOUR R.J., PATEL B.K., SCHUMANN P. Quadricoccus australiensis gen. nov., sp. nov., a beta-proteobacterium from activated sludge biomass. International Journal of Systematic and Evolutionary Microbiology. 52, 223, 2002. 